\title{
STRESS RATE PROFILE AND COPING MANAGEMENT TYPE AMONG STUDENTS IN COVID-19 PANDEMIC CONDITION
}

\author{
Pratama Y.A.*, Afifah E.D., Ilmi I.Q., Hikmat H.R., Hermawan \\ J.E.N., Damayanti P.A. and Wahyudi S. \\ Faculty of Pharmacy, Universitas Airlangga, Indonesia
}

\begin{abstract}
Coronavirus Disease 2019 (COVID-19) has changed people's habits nowadays. Every aspect of daily living was affected, mainly by people's health, economy, politics, national defense for the macro problems, and the micro problems such as the social living of human beings and psychological aspect of an individual. COVID-19 brings difficult conditions for almost all of the people in the world. The hard condition can make an individual become stressed and have to adapt to the situation by doing the coping strategies. This research aims to find the profile of stress rate, then the source of the stress condition, type of coping managements and coping have been done as coping strategies that have been done by Universitas Airlangga Students in COVID-19 pandemic condition. This research is descriptive research conducted on Universitas Airlangga students around September - October 2020. This cross-sectional research was to collect the information by using a questionnaire with a total of 45 questions. The number of samples is 121 respondents with criteria as an active Universitas Airlangga student in bachelor degree. The information was collected then analyzed with the SPSS application. From this research, we know that from 121 respondents as Universitas Airlangga students, most of them had a moderate stress level (74\%), followed by a high perceived stress level (23\%), and a low level (3\%). Then, the coping managements that have been done by them majority doing the problem-focused coping to adapt with the stress condition and the coping strategies that have been done in COVID-19 pandemic condition is following health protocol as the government policy.
\end{abstract}

Keywords: stress profile, coping management, students, COVID-19

\section{Introduction}

Starting in December of 2019, COVID-19 spreads worldwide. Rapid infection rate and human-tohuman transmissions characterize COVID-19. Nowadays, COVID-19 is one of the biggest health crises in the world. The number of patients and deaths is increasing each day. In Indonesia, in December 2020, there were about 600,000 cases with about 20,000 deaths (CSSE, 2020). Facing this dramatic emergency, the Government implemented extraordinary measures to limit viral transmission. In this critical situation, everyone's life changed due to restrictions of movement and social contacts. Although the pandemic has been under effective control, the numbers of confirmed and suspected cases continue to rise simultaneously depends on the attitude of the people. The impact of the pandemic can be seen in the weakening of economic growth, such as economic recession for some countries and the increasing number of unemployment. The other impact goes to the education field. Many institutions must have done the online class by studying from home. That does not just impact the teaching process but the psychological aspect of the students (Livana et al., 2020).

Stress condition is a condition that stressing the psychological aspect of an individual in a way to reach his goals. COVID-19 changed the way people live and communicate, causing major life 
disruptions across countries. In the psychology literature, life disruptions or the threat of a disruption in individuals' life is often conceptualized as stressful life events (Thoits, 1983). The advent of stressful life events can cause psychological disturbances for individuals' current and future life (Holmes and Masuda, 1974). The psychological impact of life disruptions can be significant for emerging adults, as college students are found to be particularly vulnerable to negative events since they are still undergoing developmental transitions (Cohen et al., 1987). Most recent studies (Carney et al., 2020) have reported that youths who faced life disruptions during COVID-19 were found to have higher levels of perceived stress. Cohen et al. (1988) defined perceived stress as the level of individuals' stress given a life situation. However, stress-coping skills allow individuals to mitigate the effects of life disruptions on perceived stress. Students with active coping skills are found to have a higher chance of ultimately completing their degrees (Bowman, 2010) and less likelihood of having suicide ideation (Zhang et al., 2012).

In the way to solve the stress condition, an individual will respond with any adaptation processes. Then, the adaptation process is called coping stress. The other word, that means an active act to adapt to the situation containing stressfulness as the main component (Lazarus and Folkman, 1984). Two strategies can be done to adapt to the condition, problem-focused and emotion-focused coping. Problem-focused coping is a strategy of an individual to change the situation or the problem, it can be by avoiding or facing the problem that is categorized as confrontation, seeking social support, and planned problem-solving. Emotion-focused coping is a strategy of an individual to change the emotion of himself. It can be categorized as self-control, self-withdrawal, re-evaluation positively, dealing with responsibility, and avoiding the changes in the situation (Lazarus and Folkman, 1984). In the COVID-19 pandemic era, many things could be the stress sources, such as boredom at home so we could not meet each other, and a lot of homework that has to be done (Livana et al., 2020). Then, many of them are solved by coping management done by students. Now, Health protocols can be one of the coping strategies to adapt to the new situation of the world being. Many institutions were held the health protocols to prevent the spreading of the coronavirus and push the number of cases and death.

\section{Objective}

This research is conducting the profile of stress rate, then the source of the stress condition, type of coping managements and coping have been done as coping strategies that have been done by Universitas Airlangga Students in COVID-19 pandemic condition

\section{Research Method}

This research is descriptive research conducted on Universitas Airlangga Students around September - October 2020. The number of samples is 121 respondents with criteria as an active Universitas Airlangga student in bachelor degree. This cross-sectional research was to collect the information by using a questionnaire with a total of 45 questions with informed consent before. 8 Questions about the stress rate profile, 7 questions about the source of stress, 17 questions about the coping managements, and 13 questions about the example of coping strategies that have been done by the respondents. This questionnaire is an online form that was validated with content validation with 40 students and the question was brought from previous research. Perceived Stress Scale from Cohen and Williamson 
(1988) and Coping Strategy adapted from Baloran (2020) with the reliability score above 0,7. The information was collected then analyzed with the SPSS application.

\section{Results}

Table 1: Demographic Information

\begin{tabular}{ll}
\hline Gender & $\mathrm{N}(\%)$ \\
\hline Male & $17(14.05)$ \\
Female & $104(85.95)$ \\
Total & $121(100)$ \\
\hline Age & $\mathrm{N}(\%)$ \\
\hline 16 & $1(0.83)$ \\
18 & $8(6.61)$ \\
19 & $25(20.66)$ \\
20 & $48(39.67)$ \\
21 & $33(27.27)$ \\
22 & $4(3.31)$ \\
23 & $2(1.65)$ \\
Total & $121(100)$ \\
Mean & $20,02 \pm 1.08$ \\
\hline Domicile & $\mathrm{N}(\%)$ \\
\hline Surabaya Area & $52(42.98)$ \\
East Java, exclude Surabaya & $44(36.36)$ \\
Java Area, exclude East Java & $17(14.05)$ \\
Others & $8(6.61)$ \\
Total & $121(100)$ \\
\hline
\end{tabular}

\section{Stress Rate Profile}

Low 1 Moderate $\mathbf{1}$ High Perceived

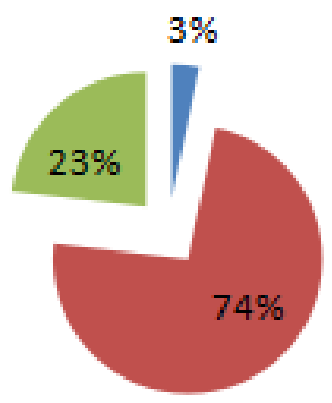

Figure 1: The diagram of respondents according to their stress rate profile is divided into the low, moderate, and high perceived stress rate 
The majority of respondents experienced a moderate stress rate, namely as much as $74 \%$. Next to the moderate level, $23 \%$ got the high perceived stress rate, and 3\% remaining got the low-stress rate.

Table 2: Source of Stress

\begin{tabular}{lll}
\hline No. & Source & $\mathrm{N}(\%)$ \\
\hline 1. & Homework & $103(85.12)$ \\
2. & Bored at home & $70(57.85)$ \\
3. & Teaching process goes boring & $87(71,90)$ \\
4. & Could not meet other people & $78(64.46)$ \\
5. & Could not join the teaching process because of & $24(19.83)$ \\
& internet problem & $62(51.24)$ \\
6. & Could not do hobbies as usual & $79(65.29)$ \\
7. & Could not apply the practice & \\
\hline
\end{tabular}

Table 3: Coping Managements

\begin{tabular}{lll}
\hline Coping Management Type & Gender & $\mathrm{N}(\%)$ \\
\hline Problem-Focused Coping & Male & $12(9.92)$ \\
& Female & $64(52.89)$ \\
Emotion-Focused Coping & Male & $5(4.13)$ \\
& Female & $40(33.06)$ \\
Total & & $121(100)$ \\
\hline
\end{tabular}

Table 4: Coping strategies that have been done during COVID-19 Pandemic

\begin{tabular}{lll}
\hline No. & Source & $\mathrm{N}(\%)$ \\
\hline 1. & Following the health protocols & $121(100)$ \\
2. & Reading the COVID-19 information & $111(91.74)$ \\
3. & Avoiding to go to public places & $104(85.95)$ \\
4. & Doing relaxation & $95(78.51)$ \\
5. & Studying the Scripture & $86(71.07)$ \\
6. & Communicating with each other & $101(83.47)$ \\
7. & Using the social media & $116(95.87)$ \\
8. & Playing online game & $60(49.59)$ \\
9. & Doing self-motivation & $102(84.30)$ \\
10. & Calling psycholog ot psychiatry & $6(4.96)$ \\
11. & Keeping busy & $88(72.37)$ \\
12. & Avoiding miss information about COVID-19 & $97(80.17)$ \\
13. & Showing off the emotion by crying, shouting, and & $46(38.02)$ \\
& angry & \\
\hline
\end{tabular}




\section{Discussion}

The demographic characteristics of the respondents are shown in Table 1. Of the 121 respondents who had filled the questionnaire is online, as many as 104 (85.95\%) in whom various sex female. The range of age of the respondents was 16-23 years with mostly aged 20 years (39.67\%). "Seniors are the adult or mature young which already has responsibility for their actions, attitudes, desires which are owned, and not rely on others" (Atwater \& Duffy, 2005). Most of the respondents live in the Surabaya area $(42.98 \%)$.

\section{Stress Rate Profile}

The diagram of respondents according to their stress rate profile is divided into the low, moderate, and high perceived levels. The majority of respondents experienced a moderate stress rate, namely as much as $74 \%$. Next to the moderate level, $23 \%$ got the high perceived stress rate, and $3 \%$ remaining got the low-stress rate. This research had the same results as the study by Cao (2020) that from 7143 students, as many as $21.3 \%$ of them had mild anxiety, while $2.7 \%$ had moderate anxiety, and $0.9 \%$ had more severe anxiety. In the study another in the United States, as many as $71 \%$ of a total of 195 students indicated resources to Increased stress and anxiety during a pandemic COVID-19 (Son et al., 2020)

\section{Source of Stress}

The results of the study indicate the existence of various kinds of sources of stress, the majority with a percentage of $85.12 \%$ (103) is of the number of homework that is given, followed by the teaching process goes to boring as much as $71.90 \%$ (87), could not apply the practice as much as $65.29 \%$ (79), could not meet other people as much as $64.46 \%$ (78), and could not do their hobbies as usual $51.24 \%$ (62), and could not join the teaching process because of internet problem as much as $19.83 \%$ (24). Then, that source of stress majority come from the number of homework which the students got. The application of study from home because of COVID-19 makes the teaching process became less effective. This result has the same point in previous research (Livana et al., 2020) that homework was the main stress source. An earlier study by Main (2011) found that experiences of SARS-related stressors were positively associated with psychological symptoms for Chinese students during the outbreak. So it is suspected that in a pandemic COVID-19, this will affect the mental public anyway, even in the people who are not as directly contaminated with the disease, the influence of psychological look very significant. Three triggers were identified as stressors in students during the COVID-19 pandemic, academic pressure (Barker, 2018; Yang, 2021), social and interpersonal pressure (Coiro, 2017; Siegel, 2018; Yang, 2021), and environmental pressure (Metzger, 2017). Other studies also mention an increase in stress levels due to academic pressures such as difficulty for concentration $(173 ; 89 \%)$, and an increase in concerns on academic performance $(159 ; 82 \%)$ (Son et al., 2020).

\section{Coping Management}

Coping is the set of psychological responses to perceptions of threat with the aim to prevent or diminish threat, harm, and loss or to reduce associated distress (Carver, 1997). In this study, coping management is divided into two types, namely problem-focused coping and emotion-focused coping. 
The result is as many as 64 women and 12 men using problem-focused coping, while 40 men and five women more using emotion-focused coping. Some studies said that short-term healing of stress condition is doing the problem-focused coping, but it would be useless when it is done in long-term healing of stress condition (Achmadin, 2015).

\section{Coping Strategies}

Coping located is the effort of individuals to cope with something internally and externally. Metaanalyses indicate that engagement with a set of "functional" coping strategies is associated with better physical and mental health in individuals facing a range of stressors, such as traumatic events (social stress, bullying) or health-related conditions (HIV, cancer, and diabetes) (Raskauskas and Huynh, 2015). In addition, outbreaks of viral infections are considered among the conditions that coping strategies have been found to play an important role on emotional responses and the development of psychological problems (Zhong et al., 2013). Strategies coping aim to address the situation of the pressure, challenge, and burdensome, exceeds the source power (Maryam, 2017). From the research, it found that there are some coping strategies are used by students, in the order of three biggest are following the protocol of health (121), using social media (116), and reading COVID-19 information (111). In addition to the three mentioned above, there are more coping strategies that have done by avoiding going to public places, doing relaxation, studying the scripture, communicating with each other, playing an online game, doing self-motivation, calling psychology or psychiatry, keeping busy, avoiding miss information about COVID-19, and showing off the emotion by crying, shouting, and angry. Tahara et al. (2021) distinguish coping strategies become eight categories, they are confrontive coping (changing situations and involves taking risks), distancing (taking distance to detach ourselves), self-control (regulating the actions and feelings of their own), seeking social support (having efforts to support real or emotional), accepting responsibility (admitting responsibility to improve the situation), escape-avoidance (escaping themselves to avoid problems), and using many of considerations of problem-solving (focusing to change the situation), and positive reappraisal (creating meaning positive for growth in private).

World Health Organization (2020), also issued as an attempt to coping illustration with stress during the 2019-nCOV outbreak that feeling sad, stressed, confused, scared, and angry during a pandemic was normal. They can be solved by talking to others who believed. Furthermore, if all of the people should keep themself at home, it is important to take the healthy lifestyle such as proper diet, sleep, exercise, and social contact to the people in the house. Limiting concerns, for example, spending time watching movies or other media, looking for new skills and hobbies that can manage our emotions during the pandemic period.

Another way that might facilitate the most students when doing the learning process, such as reducing course load, opening examinations books, and other perks on assessment requirements, can also contribute to reducing stress levels. Behavioral coping maladaptive such as denial and disengagement has proven to be a predictor of significant depression in the adult young. In contrast, adaptive coping such as acceptance and proactive behavior is known to have a positive impact on mental health. The majority of participants (76\%) with an increase in stress level due to an outbreak of COVID-19 explained that they use a variety of ways to help themselves overcome the stress and anxiety during the pandemic (Son et al., 2020). 
The limitation of this study is there is no analysis for the correlation among the demographic data, level of stress condition, and type of coping managements. For further study, there should explain a correlation between the demographic data, such as age, gender, a load of homework, level of stress condition, and type of coping managements.

\section{Conclusion}

COVID-19 has changed the way students live and makes them adapt to new situations. From this research, we know that from 121 respondents as Universitas Airlangga students, most of them had a moderate stress rate $(74 \%)$, followed by a high perceived stress rate $(23 \%)$, and with a low rate $(3 \%)$. The main problem as a stress source is homework and followed by the teaching process and the practice that cannot be applied. Then, the coping managements that have been done by them majority doing the problem-focused coping to adapt with the stress condition and the coping strategies that have been done in COVID-19 pandemic condition is following health protocol as the government policy. Based on the results above, the stress conditions on this pandemic have increased. Every individual has different levels, sources of stress, and coping strategies to adapt to the situations.

\section{References}

Achmadin, Anggit Jiwandani. (2015). Thesis. Strategi Coping Stres pada Mahasiswa Baru Fakultas Psikologi Universitas Muhammadiyah Malang. Malang : Fakultas Psikologi Universitas Muhammadiyah Malang

Atwater, E \& Duffy, K. G. (2005). Psychology for living: Adjusment, Growth and Behaviour Today (8th Edition). New Jersey: Pearson Prentice.

Baloran, Erick T. (2020). Knowledge, Attitudes, Anxiety, and Coping Strategies of Students during COVID-19 Pandemic. Journal of Loss and Trauma, Vol. 25, No. 8

Barker, E.T., Howard, A.L., Villemaire-Krajden R. \& Galambos, N.L. (2018). The Rise and Fall of Depressive Symptoms and Academic Stress in Two Samples of University Students. J Youth Adolesc. ; 47: 1252-66. pmid: 29470761

Bowman, N. A. (2010). The Development Of Psychological Well-Being Among First-Year College Students. Journal of College Student Development, 51(2), 180-200. doi:10.1353/csd.0.0118

Cao, W., Fang, Z., Hou, G., Han, M., Xu, X., Dong, J. \& Zheng, J. (2020). The Physiological Impact of the COVID-19 Epidemic on College Students on China. Journal of Phychiatry Research.

Carney, G. Knepple (2020). Age Moderates Perceived COVID-19 Disruption on Well-Being. The Gerontologist. Advance online publication.

Carver, C. S., (1997). "You want to measure coping but your protocol'stoo long: consider the Brief COPE,'International Journal of Behavioral Medicine, vol. 4, no. 1, pp. 92-100

Coiro, M.J., Bettis, A.H.\& Compas, B.E. (2017). College Students Coping with Interpersonal Stress: Examining a Control-Based Model of Coping. J Am Coll Health.; 65: 177-86. pmid: 27911672

Cohen, L. H., Burt, C. E. \& Bjorck, J. P. (1987). Life stress and adjustment: Effects of life events experienced by young adolescents and their parents. Developmental Psychology, 23(4), 583. doi:10.1037/0012-1649.23.4.583

Cohen, S. \& Williamson, G. (1988). Perceived Stress in a Probability Sample of the United States. The Social Phsycology of Health

CSSE. (2020). COVID-19 Data in Indonesia. Accessed in Dec, (2020) 
Holmes, T. , \& Masuda, M. (1974). Life change and illness susceptibility. In B. S. Dohrenwend \& B. F.Dohrenwend (Eds.), Stressful life events: Their nature and effects (pp. 45-72). New York: John Wiley \& Sons

Lazarus, R. S. \& Folkman, S. (1984) Stress, Appraisal, and Coping. New York, NY: Springer.

Livana, P. H., Mubin, M. F., Basthomi, Y. (2020). “Tugas Pembelajaran” Penyebab Stres Mahasiswa Selama Pandemi COVID-19. Jurnal Ilmu Keperawatan Jiwa, Vol. 3, No. 2

Main A, Zhou Q, Ma Y, Luecken LJ, Liu X. (2011). Relations of SARS-Related Stressors and Coping to Chinese College Students' Psychological Adjustment During the 2003 Beijing SARS Epidemic. J Couns Psychol.; 58: 410-23. pmid: 21574694

Metzger IW, Cooper SM, Ritchwood TD, Onyeuku C, Griffin CB. (2017). Profiles of African American College Students' Alcohol Use and Sexual Behavior: Associations with Stress, Racial Discrimination, And Social Support. J Sex Res.; 54: 374-85. pmid: 27215314

Raskauskas, J., and Huynh, A., 2015. "The process of coping withcyberbullying: a systematic review,"Aggression and ViolentBehavior, vol. 23, pp. 118-125

Siegel DM, Burke TA, Hamilton JL, Piccirillo ML, Scharff A, Alloy LB. (2018). Social Anxiety and Interpersonal Stress Generation: The Moderating Role of Interpersonal Distress. Anxiety Stress Coping.; 31: 526-38. pmid: 29855206

Son, C., Eysenbach, G., Fagherazzi, G., Torous, J., (2020). Effect of COVID-19 on College Students' Mental Health in the United States: Interview Survey Study. Journal of Medical Internet Research

Tahara, M., Mashizume, Y ., Takahashi, K. (2021). Coping Mechanisms: Exploring Strategies Utilized by Japanese Healthcare Workers to Reduce Stress and Improve Mental Health during the COVID-19 Pandemic. Int. J. Environ. Res. Public Health, 18, 131.

Thoits, P. A. (1983). Dimensions of Life Events That Influence Psychological Distress: An Evaluation and Synthesis of the Literature. In H.Kaplan, \& R.Kessler (Eds), Dimensions of Life Events That Influence Psychological Distress: An Evaluation and Synthesis of the Literature (pp. 4572). New York: Academic Press doi:10.1016/B978-0-12-397560-7.50007-6

Yang, C., Chen, A., Chen, Y. (2021). College Students' Stress and Health in the COVID-19 Pandemic: The Role of Academic Workdload, Separation from School, and Fears of Contaagion

Zhang, X., Wang, H., Xia, Y., Liu, X., Jung, E. (2012). Stress, Coping and Suicide Ideation in Chinese College Students. Journal of Adolescence, 35(3), 683-690.

Zhong, W., Kim, Y., and Jehn, M., (2013). "Modeling dynamics of aninfluenza pandemic with heterogeneous coping behaviors: casestudy of a 2009 H1N1 outbreak in Arizona,"Computational \&Mathematical Organization Theory, vol. 19, no. 4, pp. 622-645 